Article

\title{
Cloning, Characterization and Expression Pattern Analysis of a Cytosolic Copper/Zinc Superoxide Dismutase (SaCSD1) in a Highly Salt Tolerant Mangrove (Sonneratia alba)
}

\author{
Enze Yang ${ }^{1,2, \dagger}$, Shanze $\mathrm{Yi}^{1,2, \dagger}{ }^{\dagger}$, Fang Bai ${ }^{3}$, Dewei Niu ${ }^{1,2}$, Junjie Zhong ${ }^{1,2}$, Qiuhong Wu ${ }^{1,2}$, \\ Shufang Chen ${ }^{4}$, Renchao Zhou ${ }^{4, *}$ and Feng Wang ${ }^{1,2, *}$ \\ Received: 15 September 2015; Accepted: 26 November 2015; Published: 22 December 2015 \\ Academic Editor: Hatem Rouached \\ 1 College of Pharmacy, Jinan University, Guangzhou 510632, China; yangenze@foxmail.com (E.Y.); \\ yishanze317@163.com (S.Y.); 18739977531@163.com (D.N.); 18825084106@163.com (J.Z.); \\ qiuhong6506@126.com (Q.W.) \\ 2 Guangdong Provincial Key Laboratory of Pharmacodynamic Constituents of TCM and New Drugs \\ Research, Jinan University, Guangzhou 510632, China \\ 3 School of Life Sciences, Shenzhen University, Shenzhen 518060, China; 15016733519@163.com \\ 4 State Key Laboratory of Biocontrol and Guangdong Provincial Key Laboratory of Plant Resources, \\ School of Life Sciences, Sun Yat-Sen University, Guangzhou 510275, China; chsuf@mail.sysu.edu.cn \\ * Correspondence: zhrench@mail.sysu.edu.cn (R.Z.); jnubiopharm@126.com (F.W.); \\ Tel.: +86-20-8411-1164 (R.Z.); +86-20-3837-5022 (F.W.) \\ + These authors contributed equally to this work.
}

\begin{abstract}
Mangroves are critical marine resources for their remarkable ability to tolerate seawater. Antioxidant enzymes play an especially significant role in eliminating reactive oxygen species and conferring abiotic stress tolerance. In this study, a cytosolic copper/zinc superoxide dismutase (SaCSD1) cDNA of Sonneratia alba, a mangrove species with high salt tolerance, was successfully cloned and then expressed in Escherichia coli Rosetta-gami (designated as SaCSD1). SaCSD1 comprised a complete open reading frame (ORF) of $459 \mathrm{bp}$ which encoded a protein of 152 amino acids. Its mature protein is predicted to be $15.32 \mathrm{kDa}$ and the deduced isoelectric point is 5.78. SaCSD1 has high sequence similarity $(85 \%-90 \%)$ with the superoxide dismutase $(C S D)$ of some other plant species. SaCSD1 was expressed with $30.6 \%$ yield regarding total protein content after being introduced into the pET-15b (Sma I) vector for expression in Rosetta-gami and being induced with IPTG. After affinity chromatography on Ni-NTA, recombinant SaCSD1 was obtained with 3.2-fold purification and a specific activity of $2200 \mathrm{U} / \mathrm{mg}$. SaCSD1 showed good activity as well as stability in the ranges of $\mathrm{pH}$ between 3 and 7 and temperature between 25 and $55{ }^{\circ} \mathrm{C}$. The activity of recombinant $S a C S D 1$ was stable in $0.25 \mathrm{M} \mathrm{NaCl}$, Dimethyl Sulphoxide (DMSO), glycerol, and chloroform, and was reduced to a great extent in $\beta$-mercaptoethanol, sodium dodecyl sulfate (SDS), $\mathrm{H}_{2} \mathrm{O}_{2}$, and phenol. Moreover, the SaCSD1 protein was very susceptive to pepsin digestion. Real-time Quantitative Polymerase Chain Reaction (PCR) assay demonstrated that SaCSD1 was expressed in leaf, stem, flower, and fruit organs, with the highest expression in fruits. Under $0.25 \mathrm{M}$ and $0.5 \mathrm{M}$ salt stress, the expression of SaCSD1 was down-regulated in roots, but up-regulated in leaves.
\end{abstract}

Keywords: Sonneratia alba; copper/zinc superoxide dismutase; protein expression; activity and stability; salt stress 


\section{Introduction}

Mangroves play an important role in protecting coastal areas by buffering erosion from waves and thus reducing damage from typhoons and sequestering carbon [1,2]. Sonneratia alba, one of the most widespread and salt-resistant mangrove trees, grows in the swampy salt water zones of tropical and subtropical coasts [3]. It can adapt to salinities varying from fresh water to sea water [4,5]. Although the increasing ecological importance of mangroves is known, the molecular mechanisms elucidating their adaptation to extremely high saline intertidal habitats remain elusive. Abiotic external stress factors, such as drought, salinity, strong light intensity, extreme temperature, and heavy metals, may result in oxidation stress with the accumulation of Reactive oxygen species (ROS), causing huge inhibition in photosynthesis and great cellular damage [6]. The resulting excessive ROS from the extreme salinity of the intertidal environments must be removed efficiently [6-8]. superoxide dismutases (SODs) function as the first line of defense in the enzymatic pathway of defense against free oxygen radicals [9]. In plants, SODs can be divided into three distinct groups based on different metal ions: copper/zinc SOD (Cu/Zn-SOD), manganese SOD (Mn-SOD), and iron SOD (Fe-SOD) [10]. Mn-SOD only exists in mitochondria and Fe-SOD only exists in chloroplasta, while CSD is the most abundant SOD in plants, and has been mainly located in the cytosol. In general, the activity of antioxidant enzymes and plant resistance strength has a positive correlation[11]. It has been reported that the SOD activities of field-grown mangroves are nearly 40 times higher than those in some common crop plants such as the pea [12]. Moreover, certain antioxidative enzymes against activated oxygen under salt stress, such as ascorbic peroxidase (APX), guaiacol peroxidase (GPX), glutathione reductase (GR), and superoxide dismutase (SOD), were found to be elevated in one mangrove species, Bruguiera parviflora [13].

Although CSDs have been cloned from a number of plant species, such as sweet potato [14], pea [15], and rice [16], there have been limited reports in two mangrove species, Avicennia marina and Bruguiera gymnorhiza [6], due to insufficient transcriptomic and genomic data in the public databases. Moreover, characterization of CSDs has not been studied in highly salt-tolerant mangrove plants.

SOD is widely used in clinical therapy, medicines, food, and cosmetics as an efficacy factor or as an additive [17-21], such as in some beer and revitalizers. For instance, exogenous SOD added in a yeast mixture could improve the growth and vitality of yeast cells, and ultimately improve the fermentation degree [22]. Due to extensive applications of SODs in food and cosmetic industries as well as for various medicinal purposes, it is imperative to resolve the problem of low activity and stability. In this study, a novel SaCSD1 from $S$. alba was cloned and the recombinant enzyme was expressed in E. coli. In addition, we analyzed the sequence and examined the activity and stability of the enzyme at different $\mathrm{pHs}$, temperatures, and media. The expression of SaCSD1 in different organs was detected. The altered expression of SaCSD1 in roots and leaves after treatment with different salt concentrations was also detected. Its relationship with the salt resistance properties of the plant was also explored preliminarily. The present work may lay the foundation for plant genetic engineering for stress resistance improvement, and the production of a novel $\mathrm{Cu} / \mathrm{Zn}-\mathrm{SOD}$ enzyme as an additive in healthcare products.

\section{Results}

\subsection{Cloning of SaCSD1 and Sequence Analysis}

The sequence of $S a C S D 1$ was cloned for further analysis and characterization and its cDNA sequence was submitted to GenBank (Accession No. KF888631). The SaCSD1 cDNA contained a 459-bp coding sequence, which encodes a protein of 152 amino acids (Figure 1a) with a predicted molecular weight of approximately $15.32 \mathrm{kDa}$ and a $\mathrm{pI}$ of 5.78. We have concluded that SaCSD1 has no signal peptide through the web site (http://www.cbs.dtu.dk/services/SignalP/). The result suggests that $S a C S D 1$ exists in cytosol. 
Comparison of the SaCSD1 deduced amino acid sequence showed high similarity (85\%-90\%) to the CSDs of other plant species, including several dicots and monocots (Table 1). Furthermore, multiple sequence alignment of these CSDs showed SaCSD1 contained potential binding sites for copper (H42, H45, H62, and H119) and zinc (H62, H70, H79, and D82) (Figure ??b). This result was in agreement with the previous studies $[9,15]$.

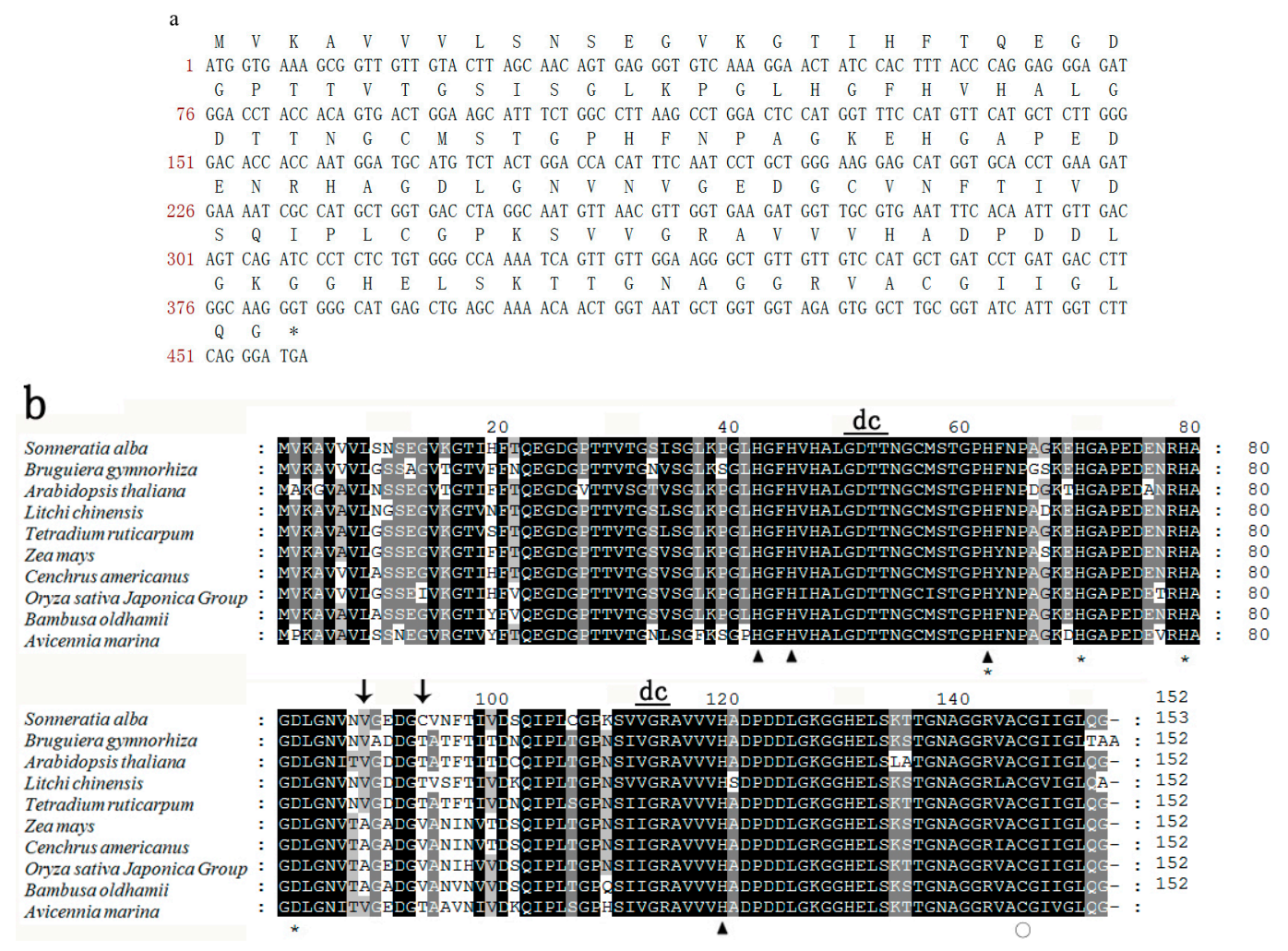

Figure 1. Sequence analysis of SaCSD1. (a) Coding sequence and amino acid sequence of SaCSD1; (b) Amino acid sequence alignment of CSDs for Sonneratia alba and other species. Triangle denotes copper ion binding sites, asterisk denotes zinc ion binding sites, circle denotes amino acids which form disulphide bonds, arrow indicates changes in the amino acids at the 89th and 94th positions between the plant species belonging to the Poaceae family and other families, and $d c$ represents amino acids involved in dimer contact. Residues that are identical among the sequences are given a black background, and similar residues are in a gray background. The remaining residues are in a white background.

Table 1. Amino acid sequence similarity of superoxide dismutases (CSDs) between S. alba and other plant species.

\begin{tabular}{ccc}
\hline Species & GenBank Accession Number & Identity \\
\hline Tetradium ruticarpum & AFF57842.1 & $90 \%$ \\
Bruguiera gymnorhiza & BAB78597.1 & $85 \%$ \\
Litchi chinensis & ABY65355.1 & $89 \%$ \\
Avicennia marina & ACA50531.1 & $84 \%$ \\
Arabidopsis thaliana & P24704.2 & $86 \%$ \\
Oryza sativa & AAA33917.1 & $85 \%$ \\
Cenchrus americanus & ABP65325.1 & $87 \%$ \\
Zea mays & NP001105704.1 & $85 \%$ \\
Bambusa oldhamii & ACX94084.1 & $87 \%$ \\
\hline
\end{tabular}




\subsection{Expression, Purification, and Western Blot Analysis of SaCSD1}

After electrophoresis, gray scanning analysis showed that the recombinant plasmid containing the SaCSD1 gene was induced to express the protein with $30.6 \%$ yield in terms of total protein content. The expressed fusion protein was found in soluble form, and the purified protein was confirmed by SDS-PAGE electrophoresis, with a single band of approximately $16 \mathrm{kDa}$ (Figure 2a). After affinity chromatography, recombinant SaCSD1 was obtained with 3.2-fold purification relative to the supernatant of the lysis after ultrasonication, and a specific activity of $2200 \mathrm{U} / \mathrm{mg}$. Bovine CSD (diluted to $1000 \mathrm{U} / \mathrm{mg}$ ) ordered from Sigma was used as the standard. Western Blot analysis using anti-His tag antibody confirmed the presence of the protein (Figure 2b).

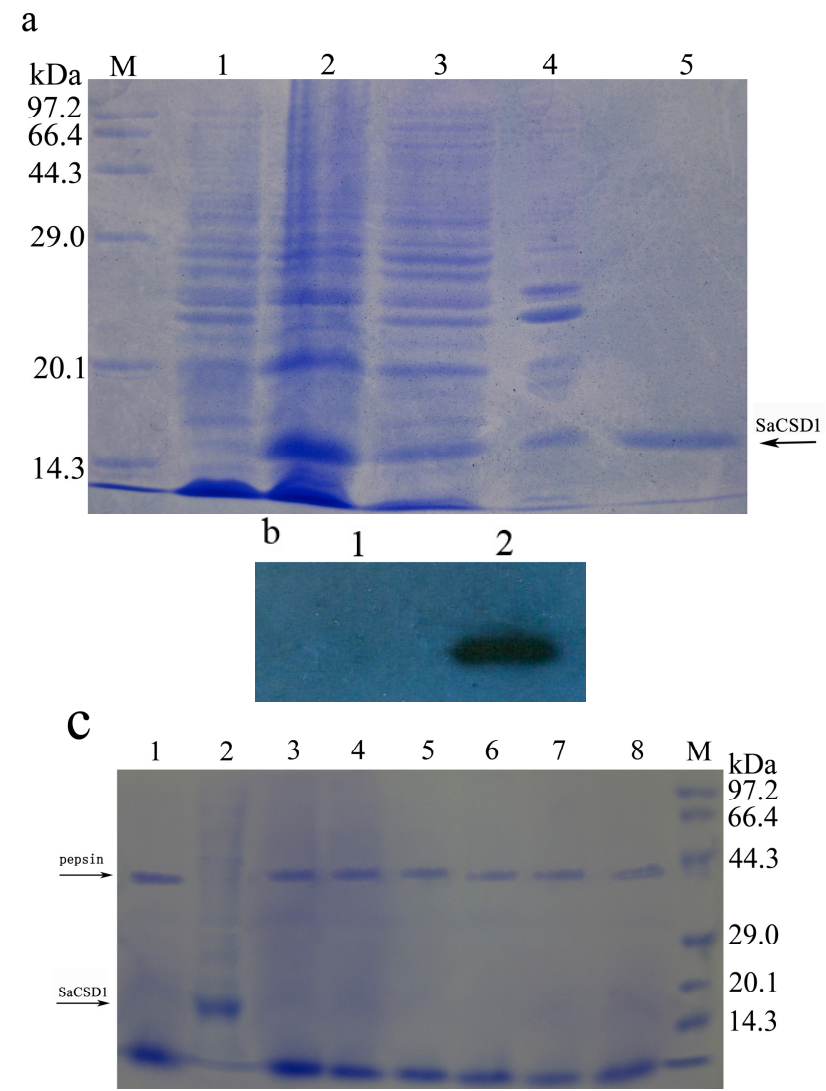

Figure 2. Expression, purification, Western Blot and pepsin digestion analysis of recombinant SaCSD1 protein. (a) Electrophoretogram of SaCSD1 protein. Lane M, protein marker; lane 1, uninduced E. coli lysate; lane 2, IPTG-induced E. coli lysate; lane 3, supernatant of the lysis after ultrasonication; lane 4, pellets of the lysis after ultrasonication; lane 5, the purified SaCSD1; (b) Western Blot detection of fusion protein with anti-His mAb. Lane 1, uninduced E. coli lysate; lane 2, the purified SaCSD1; (c) In vitro standardized pepsin digestion assay of SaCSD1 protein. Lane 1, the reaction without SaCSD1; lane 2, the reaction without pepsin; lane 3-8, the reaction in different times $(0.5,2,5,10$, 20, $30 \mathrm{~min})$; M, protein marker.

\subsection{Effects of $p H$, Temperature, Chemicals, and Salt on Activity of SaCSD1}

The purified SaCSD1 had a functional $\mathrm{pH}$ range of 3.0-7.0 with more than $70 \%$ activity (highest at $\mathrm{pH}$ 6.0). The activity dropped rapidly at $\mathrm{pH}$ above 6.0 (Figure 3a), suggesting that SaCSD1 should be more stable in acidic conditions. No significant change in enzyme activity was observed when treated at $25-45{ }^{\circ} \mathrm{C}$ for up to $1 \mathrm{~h}$. Even at $75{ }^{\circ} \mathrm{C}, 60 \%$ of enzyme activity was preserved after $1 \mathrm{~h}$ of treatment (Figure $3 b$ ), suggesting that the SaCSD1 is relatively thermostable. The enzymatic activity is increased about $20 \%$ after being treated in glycerol or chloroform, which is consistent 
with the findings of Xie [23]. The enzyme still retained $90 \%$ residual activity in DMSO. In addition, $\beta$-mercaptoethanol, SDS, $\mathrm{H}_{2} \mathrm{O}_{2}$, and phenol have marked effects in reducing the activity of SaCSD1 (Figure 3c). We speculate that glycerol and chloroform may supply a hydrophobic environment that is conducive to better contact with the substrate. Both activity of SaCSD1 and AvCSD1 decrease with the increase of salt concentration, but SaCSD1 did not show significantly stronger activity on salt tolerance than AvCSD1 (Figure 3d).
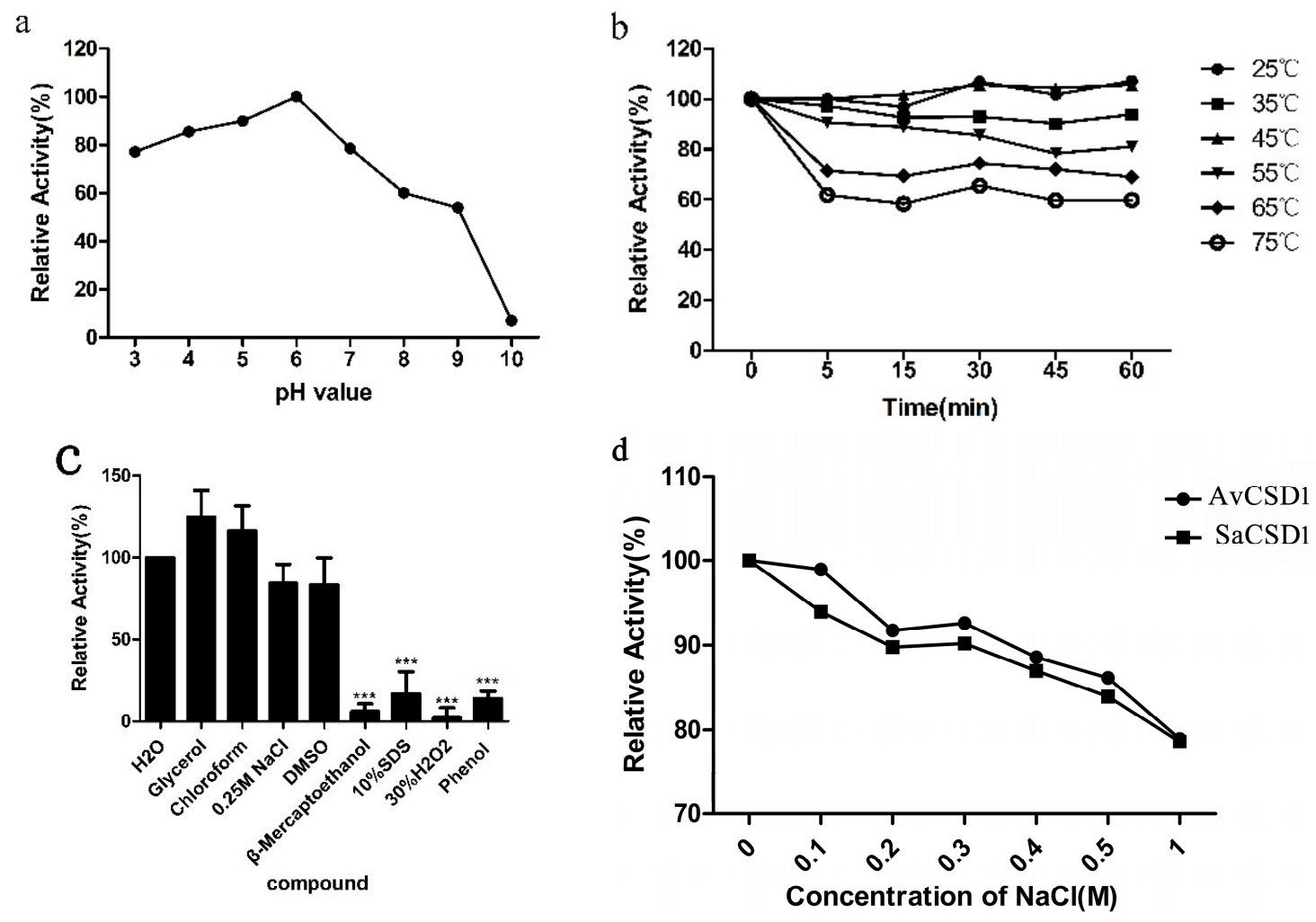

Figure 3. Effects of $\mathrm{pH}$, temperature, chemicals, and salt on the activity of the purified SaCSD1. (a) pH stability of the purified SaCSD1, with the highest activity set as $100 \%$; (b) Thermal stability of the purified SaCSD1. Activity of the enzyme without heat treatment was set as $100 \%$; (c) Effects of various chemical compounds. Activity of the enzyme treated in $\mathrm{H}_{2} \mathrm{O}$ was set as the control and *** $p<0.001$ means a significant difference from the control; (d) Effects of solutions with different salt concentrations on the activities of SaCSD1 and AvCSD1. Data are presented as the mean \pm SD of three independent experiments.

\subsection{Pepsin Digestion Characteristics of SaCSD1}

The sensitivity of the recombinant SaCSD1 to the extreme acidity and action of pepsin in the digestive tract was then examined. The relative stability of the SaCSD1 to the extremes of $\mathrm{pH}$ and pepsin protease in the mammalian gastrointestinal (GI) tract was determined by the pepsin digestibility assay $[24,25]$. The pepsin digestibility assay showed that the SaCSD1 was degraded rapidly and completely after enzymatic treatment with pepsin. No full-length proteins were detectable even after $0.5 \mathrm{~min}$ of digestion (Figure 2c). The result demonstrated that the SaCSD1 protein was very susceptive to pepsin digestion.

\subsection{Quantification of SaCSD1 Gene Expression in Different Organs and under Salt Stress}

In the expression assay, the highest transcription of the SaCSD1 was detected in fruits and the lowest in stems. The expression level in leaves and flowers was intermediate (Figure 4a). After being treated in $\mathrm{NaCl}$ solution for seven days, the highest expression of the SaCSD1 in the 
roots was detected in the $0 \mathrm{mM}$ salinity, while both the $250 \mathrm{mM}$ and $500 \mathrm{mM} \mathrm{NaCl}$ treatments showed significantly reduced expression (both approximately $6 \%, p<0.001$ ). In contrast, the lowest expression of the SaCSD1 in the leaves was detected in the $0 \mathrm{mM} \mathrm{NaCl}$ treatment, and the expression was enhanced 4.8-fold $(p<0.001)$ in $250 \mathrm{mM}$ salinity and 2.9 -fold $(p<0.01)$ in $500 \mathrm{mM}$ salinity (Figure 4b).
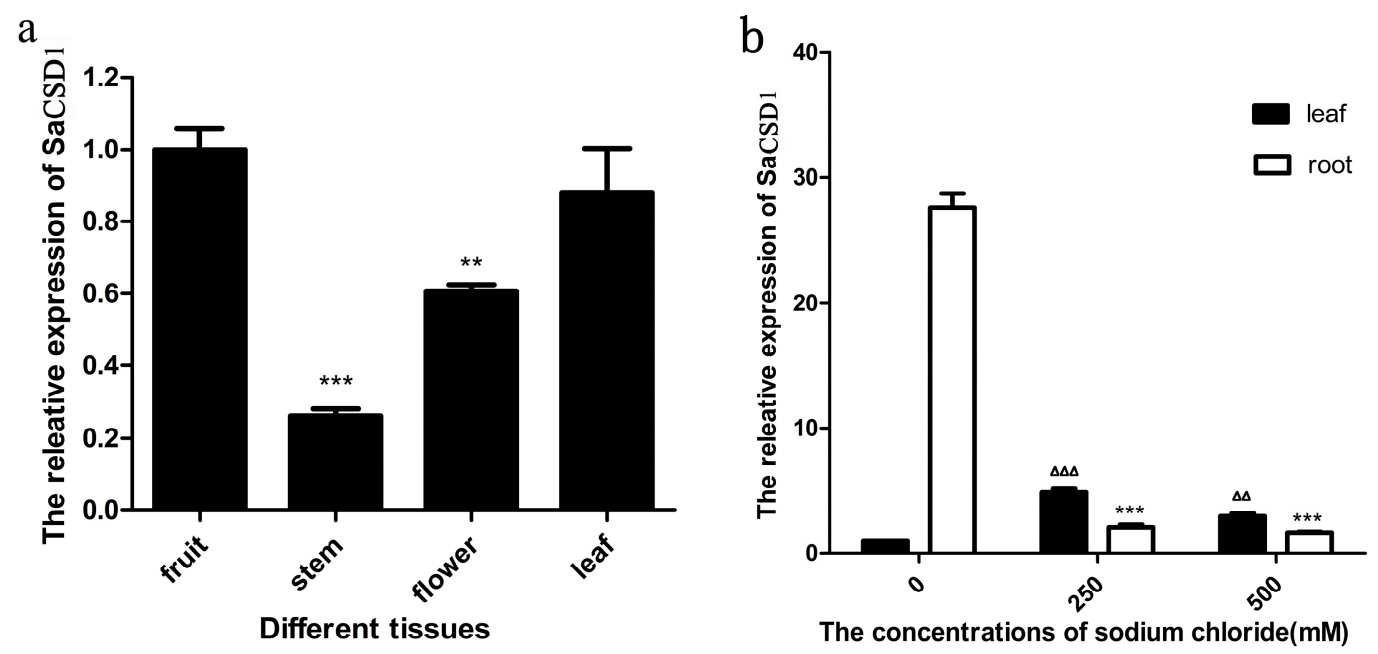

Figure 4. Real-time PCR analysis of the SaCSD1 transcript. (a) Expression of SaCSD1 in different organs. The highest expression (fruit) was set as 1.0 and ${ }^{* *} p<0.01^{* * *} p<0.001$ means significant differences from it; (b) Expression of SaCSD1 in roots and leaves treated with $\mathrm{NaCl}$ solutions. The blank group of leaves was set as 1.0 and, $\Delta \Delta p<0.01, \Delta \Delta \Delta p<0.001$ means significant differences from it, ${ }^{* * *} p<0.001$ means significant differences from the blank group of roots. CSD1 Data are presented as the mean \pm SD of three independent experiments.

\section{Discussion}

Salinity has four main constraints on plant growth: (1) salinity inhibits plant growth and development by causing osmotic stress and thus restricting $\mathrm{H}_{2} \mathrm{O}$ absorption, hence the reduced assimilation, which in turn leads to (2) oxidative stress; salt stress also leads to (3) ionic toxicity; and (4) nutrient imbalance [26,27]. Extremely high salt concentrations or long-term exposure to a salinity condition induces the inhibition of enzyme activities and the over-accumulation of reactive oxygen species (ROS) such as superoxide radical $\left(\mathrm{O}^{2-}\right)$, hydroxyl radical, and hydrogen peroxide $\left(\mathrm{H}_{2} \mathrm{O}_{2}\right)$, resulting in metabolic disturbance, lipid peroxidation, chlorophyll breakdown, and so on $[28,29]$. ROS triggered by salt stress played an important role in adaptive responses, and ROS can promote signal transduction in adaptive responses at low concentrations, while they cause damage to macromolecules such as DNA, proteins, and membrane lipids at high concentrations [30,31]. SOD is the primary scavenger in the detoxification of active oxygen species in plants, and its function is to convert superoxide to $\mathrm{H}_{2} \mathrm{O}_{2}$ and $\mathrm{O}_{2}$. Superoxide dismutase (SOD) is also one of the crucial enzymes that protects cells against oxidative damage [32]. The roles of SODs under environmental stresses have been studied extensively [32]. It was reported that salt stress leads to a significant enhancement $(88 \%)$ of total SOD activity in lentil roots due mainly to an enhancement in CSD isoforms, but leads to no significant increase in total SOD activity of leaf tissues [33]. $\mathrm{NaCl}$ stress could induce -SOD and CSD activities in thylakoids and in the stroma of Pisum sativum [34].

Studies in morphology, physiology, and ecology of mangroves have achieved much progress in the past two decades. Thanks to the development of genomic techniques, research at the genomic level has also been conducted on numerous species of mangroves recently [3]. Using Illumina sequencing technology, the transcriptome of Sonneratia alba has been uncovered [35]. Forty-five candidate salt-responsive genes (or gene families) were assumed in the transcriptome of $S$. alba and 
divided into four categories, including nine genes responsible for osmotic regulation, 12 genes that participated in ROS scavenging and detoxifying, 11 gene families related to salt uptake and transport, and 13 genes involved in signal transduction [35]. As one of the most salt-tolerant mangrove trees, Sonneratia alba grows in the low intertidal zones of tropical and subtropical coasts. The roots of Sonneratia alba are immersed in seawater, so extremely high saline intertidal habitats of Sonneratia alba are most likely associated with the roots. There are only two forms of SODS (CSD and Mn-SOD) that exist in roots. Mn-SOD only exists in mitochondria, while CSD is the most abundant SOD in plants, and has been mainly located in the cytosol. Cytosol is the major site of metabolism of cells, and it provides a stable microenvironment for the organelles. Combining a number of reports, it is likely that cytoplasmic $S a C S D 1$ may play an important role in adaptive responses to the seawater.

In the present study, we cloned and identified a cDNA sequence which encoded a novel CSD from Sonneratia alba, then expressed it in E. coli. The phylogenetic analysis reveals the presence of the conserved amino acid motifs essential for the enzyme function in the SaCSD1, which is responsible for the protein structure and catalytic function, and is even likely involved in the stabilizing conformation of CSD under harsh environmental conditions [36]. SaCSD1 shows high levels of homology to CSDs from other plants, suggesting that SaCSD1 might have the same function as that in other plants.

Real-time quantification PCR experiments showed that SaCSD1 was expressed in all tested organs, with higher transcription in fruit and leaf and lower transcription in stem and flower. Since mangroves need to deal with various environmental stress factors such as high salinity, strong light intensity, and hypoxia, $S a C S D 1$ is likely to play an important role in protecting the fruit and leaf from ROS under these stress conditions. We found that the expression of $S a C S D 1$ is down-regulated in roots under salt stress, while it is up-regulated in leaves. We also found that the old leaves near the roots turned yellow during salt stress. Zhang et al. have demonstrated that the proportion of chloroplast SOD and the SOD activity in the halophyte Suaeda salsa increased with the increase of salt concentration or time [37]. Our results showed it was possible that growth and metabolism of the roots slow down after salt stress for seven days, while cellular metabolism and photosynthesis in the leaves accelerates in response to the high salt environment.

Our study showed that SaCSD1 was very stable at acidic and neutral $\mathrm{pH}$ and varying temperatures, which makes the enzyme suitable for use in industry. The effects of $\mathrm{pH}$, temperature, and chemicals on SaCSD1 activity may lay a foundation of research for the various applications of SOD in healthcare products, cosmetics, food, and medicines. Its stable enzymatic activity in glycerol, DMSO, and chloroform may contribute to SaCSD1 protein preservation. The results of the pepsin digestibility assay suggested that SaCSD1 may not be suitable for oral products.

In conclusion, this is the first report of CSD gene cloning and expression from S. alba. Purification and characterization of SaCSD1 lay a foundation for future studies in the molecular mechanism of the adaptive evolution of mangroves. Furthermore, the biological functions and the potential therapeutic effects of SaCSD1 remain unclear. Therefore, further studies on SaCSD1 are required.

\section{Materials and Methods}

\subsection{Materials}

Sma I, Taq DNA polymerase High Fidelity Kit, CIAP, T4 DNA ligase and protein marker were purchased from Takara (Osaka, Japan). Isopropyl- $\beta$-D-thiogalactopyranoside (IPTG) and imidazole were ordered from TaKaRa (Dalian, China). Superoxide dismutase activity assay kit (WST-1 method) was purchased from Jiancheng (Nanjing, China). Mouse anti-His monoclonal antibody and Horseradish peroxidase (HRP)-labeled goat anti-mouse IgG were from TIANGEN (Beijing, China) and Proteintech (Chicago, IL, USA), respectively. Enhanced chemiluminescence (ECL) and detection reagent were obtained from Biyuntian (Haimen, China). Ni-NTA resin and SYBR Green PCR kit were purchased from QIAGEN (Hilden, Germany) and Takara (Osaka, Japan), 
respectively. Bovine $\mathrm{Cu} / \mathrm{Zn}-\mathrm{SOD}$ was ordered from Biyuntian (Haimen, China). All other reagents were analytical grade or better and commercially available.

\subsection{RNA Preparation, cDNA Synthesis and Cloning}

Sonneratia alba was collected from Qinglangang Mangrove Reserve, Wenchang, Hainan, China. Leaf (about $1 \mathrm{~cm}^{2}$ ) was ground to powder in liquid nitrogen. Total RNA was extracted and was further purified by using the modified CTAB method. Double-strand cDNA was generated using the M-MLV RTase cDNA Synthesis Kit (Takara) according to the instructions. For the amplification of SaCSD1, primers CSD1FP (5'-ATGGTGAAAGCGGTTGTTGTACT-3') and CSD1RP (5'-TCATCCCTGAAGACCAATGATAC- $\left.3^{\prime}\right)$ were designed based on the root transcriptome annotation of Sonneratia alba [8,35]. The coding region for putative mature SaCSD1 was amplified by polymerase chain reaction (PCR). The PCR fragments were subjected to electrophoresis on $0.8 \%$ agarose gel and purified using a gel purification kit (Tiangen, Beijing, China). Then the purified product was ligated into the pMD-19T vector (Takara) and transformed into E. coli DH5 $\alpha$.

\subsection{Nucleotide and Amino Acid Sequence Analysis of SaCSD1}

The clone of SaCSD1 was sequenced with the M13 forward and reverse primers. Vector NTI Advance 11 was used to analyze the nucleotide sequences, deduce amino acid sequences, and predict molecular mass and pI. Homologues of SaCSD1 amino acid sequences from other species were searched and obtained by BLASTP programs (http://blast.ncbi.nlm.nih.gov/Blast.cgi) and multiple sequence alignment was performed by Clustalx.

\subsection{Cloning into the Expression Vector, Expression and Purification of SaCSD1}

Plasmid pMD19T-SaCSD1 was obtained by using a plasmid isolation kit (Tiangen). SaCSD1 was amplified by PCR using the Pfu DNA Polymerase (Tiangen) and then ligated with pET-15b that was pretreated with Sma I and CIAP (Takara). The recombinant vector pET15b-SaCSD1 was transformed into E. coli Rosetta-gami strain (Inovogen, Darmstadt, Germany) for expression. The transformant was cultivated at $37{ }^{\circ} \mathrm{C}$ in $200 \mathrm{~mL}$ Luria-Bertani (LB) medium containing $100 \mu \mathrm{g} / \mathrm{mL}$ ampicillin, $100 \mu \mathrm{g} / \mathrm{mL}$ kanamycin, and $100 \mu \mathrm{g} / \mathrm{mL}$ chloramphenicol while shaking (220 rpm) until $\mathrm{OD}_{600}$ approached 0.5-0.6. 0.5 Mm of Isopropyl $\beta$-Dithiogalactopyranoside (IPTG) which was then added. Thereafter the protein SaCSD1 was expressed at $30{ }^{\circ} \mathrm{C}$ for $8 \mathrm{~h}$ and then the bacterial cells were harvested by centrifugation at $10,000 \times g$ for $5 \mathrm{~min}$. The cells were suspended again in $40 \mathrm{~mL}$ phosphate-buffered saline (PBS; pH 7.4) and an ultrasonic processor was used to break the cells and release the proteins. The cell lysates were centrifuged at 12,000 rpm for $2 \mathrm{~min}$ and then analyzed for protein expression by SDS-PAGE on $12 \%$ gels as described by Laemmli [38]. To purify this expressed SaCSD1, the supernatant was purified using a Ni-NTA His-Bind Resin. The purified protein was dialyzed for $24 \mathrm{~h}$ by using PBS buffer to remove imidazole.

\subsection{Western Blot Analysis}

Purified SaCSD1 was subjected to 12\% SDS-PAGE and then electrophoretically transferred to polyvinylidene fluoride (PVDF) membrane at $200 \mathrm{~mA}$ for $20 \mathrm{~min}$ and then blocked with tris-buffered saline plus $0.1 \%$ Tween 20 (TBST) with $5 \%$ skim milk at $4{ }^{\circ} \mathrm{C}$ overnight. The blocked membrane was washed three times (5 min each time) in TBST and incubated with mouse anti-His IgG (diluted 1:1000) for $2 \mathrm{~h}$ at $25^{\circ} \mathrm{C}$. After washing three times with TBST, the membranes were probed with HRP-labeled goat anti-mouse IgG (diluted 1:3000) for $2 \mathrm{~h}$ at $25^{\circ} \mathrm{C}$. Lastly, the membrane was washed four times with TBST, exposed to enhanced chemiluminescence (ECL) plus detection reagent and visualized by chemiluminescence. 


\subsection{Determination of Protein Concentration and Activity Assay of SaCSD1}

The protein concentration of SaCSD1 was assayed by the BCA method, using bovine serum albumin (BSA) as a reference substance. Superoxide dismutase activity assay kit (WST-1 method) was used to detect the SOD activity of SaCSD1. Bovine Cu/Zn SOD (diluted to $1000 \mathrm{U} / \mathrm{mg}$ ) ordered from Sigma was used as the standard.

To investigate the optimum $\mathrm{pH}$ and temperature for SaCSD1, the effect of $\mathrm{pH}$ on dismutase activity of SaCSD1 was examined at $25^{\circ} \mathrm{C}$ in the $\mathrm{pH} 3.0-10.0$ for $2 \mathrm{~h}$. Various $\mathrm{pH}$ buffers used were: 0.2 $\mathrm{M} \mathrm{Na}_{2} \mathrm{HPO}_{4}-0.1 \mathrm{M}$ Citric Acid (pH 3.0-pH 8.0) and 0.05 M Glycine-NaOH buffer (pH 9.0-10.0). Thermal stability was examined by incubating the protein in the range of $25-75{ }^{\circ} \mathrm{C}$ for $0-60 \mathrm{~min}$ [39].

To assess the enzyme inhibition, the SaCSD1 protein solution $(0.5 \mathrm{mg} / \mathrm{mL})$ was mixed with the same volume of glycerol, chloroform, dimethylsulphoxide (DMSO), $\beta$-Mercaptoethanol, 10\% sodium dodecyl sulfonate (SDS), 30\% $\mathrm{H}_{2} \mathrm{O}_{2}$, and phenol, respectively. The enzymatic activity was examined after incubation at room temperature for two hours. Control with distilled water was treated in the same way as the test samples.

We next examined if the recombinant SaCSD1 protein from S. alba exhibited stronger activity on salt tolerance than other plants by comparing the activity of CSD proteins between $S$. alba and a terrestrial non-salt tolerant plant, Amomum villosum, under salt stress. The AvCSD1 protein was cloned and expressed by using the same method described above. The two CSD protein solutions $(0.5 \mathrm{mg} / \mathrm{mL})$ were mixed with the same volume of $0,0.1,0.2,0.3,0.4,0.5$, and $1 \mathrm{M} \mathrm{NaCl}$ solutions, respectively. After incubating at $37^{\circ} \mathrm{C}$ for $4 \mathrm{~h}$, we examined the enzymatic activity.

\subsection{Pepsin Digestion Assay Conditions}

Pepsin digestion assay was conducted according to the method of Wang [24]. Briefly, $380 \mu \mathrm{L}$ of simulated gastric fluid ( $35 \mathrm{mM} \mathrm{NaCl}, 84 \mathrm{mM} \mathrm{HCl}, \mathrm{pH} 2.0,4000 \mathrm{U}$ pepsin) was preheated at $37^{\circ} \mathrm{C}$ and then $20 \mu \mathrm{L}$ of SaCSD1 protein solution $(5 \mathrm{mg} / \mathrm{mL})$ was added. The mixture was kept in water bath at $37^{\circ} \mathrm{C}$. Samples of $40 \mu \mathrm{L}$ were removed at $0.5,2,5,10,20$, and $30 \mathrm{~min}$ after initiation of the incubation and immediately stored at $20^{\circ} \mathrm{C}$. Each $40 \mu \mathrm{L}$ sample was quenched with $14 \mu \mathrm{L}$ of $200 \mathrm{mM}$ $\mathrm{NaHCO}_{3}(\mathrm{pH} 11)$ and $14 \mu \mathrm{L} 5 \times$ Laemmli buffer, then analyzed by $12 \%$ SDS-PAGE. The control samples (pepsin without test protein and reaction buffer with test protein but without pepsin) were analyzed in the same way.

\subsection{Quantification of SaCSD1 Gene Expression by Real-Time PCR}

To investigate the effects of salinity on the expression of SaCSD1, the seedlings of S. alba were planted in the greenhouse of Sun Yat-sen University under natural light conditions. After growing in the one-half Hoagland solutions for one month, these seedlings were transferred to one-half Hoagland solution with $0,250,500 \mathrm{mM} \mathrm{NaCl}$ for salt stress treatment, respectively. Tissues were harvested for RNA isolation after one week salt stress treatment. Quantitative reverse transcription-PCR in detection of the gene expression of SaCSD1 was performed on an IQTM Multicolor Real-Time Detection System (BIO-RAD, Hercules, CA, USA). Then $2 \mu \mathrm{g}$ total RNA from leaf, stem, flower and fruit was reversely transcribed, respectively. For samples under salt stress, root and leaf were used. Primers GAPDH RT-FP (5'-GTCCGTGGTTGACCTTACAGTGA-3'), GAPDH RT-RP (5'-CAATTCCAGCCTTAG CATCGAA-3 $\left.{ }^{\prime}\right)$, SaCSD1 RT-FP (5'-CAACAGTGAGGGTGTCAAAGGAA-3'), SaCSD1 RT-RP (5'-CCAGCAGGATTGAAATGTGGTC-3') were design for RT-qPCR. The reaction was performed as follows: $9 \mu \mathrm{L}$ of diluted cDNA, $0.5 \mu \mathrm{L}$ of each reverse and forward primers $(10 \mu \mathrm{M})$, and $10 \mu \mathrm{L}$ of SYBR Premix ExTaq in $20 \mu \mathrm{L}$ with one cycle of $95^{\circ} \mathrm{C}$ for $30 \mathrm{~s}$ followed by 40 cycles of denaturation $\left(5 \mathrm{~s}\right.$ at $\left.95{ }^{\circ} \mathrm{C}\right)$, and annealing $\left(20 \mathrm{~s}\right.$ at $\left.60{ }^{\circ} \mathrm{C}\right)$. The primers of glyceraldehyde 3-phosphate dehydrogenase $(\mathrm{GAPDH})$ of $S$. alba were used as the reference gene for data normalization 
and standard curve. The relative gene expression levels were reflected by relative quantification values, which were calculated using the $2^{-\Delta \Delta C t}$ method [40].

\subsection{Statistical Analysis}

All independent experiments were repeated three times. Experimental data were presented as means \pm standard deviations (SD). The GraphPad Prism 5.0 software (San Diego, CA, USA) is used to make the Student's $t$-tests or analysis of variance.

Acknowledgments: This study was supported by grants from the National Natural Science Foundation of China (31170213 and 91231106), Science and Technology Innovation Project from Department of Education of Guangdong Province (2012KJCX0017) and the research project from Administration of Traditional Chinese Medicine of Guangdong Province (20141065). We thank Maheen Gull at the University of South Florida for critical reading of the manuscript.

Author Contributions: Enze Yang and Shanze Yi conducted the protein expression, activity assay, pepsin digestion assay, and wrote the paper. Junjie Zhong and Fang Bai conducted the gene cloning, vector construction, and the RNA extraction, Qiuhong Wu conducted the transcriptome analyses, Dewei Niu and Shufang Chen conducted the RT-qPCR experiments. Feng Wang and Renchao Zhou designed the experiments and revised the paper. All authors read and agreed with the final manuscript. Feng Wang and Renchao Zhou are corresponding authors and are responsible for all contact and correspondence.

Conflicts of Interest: The authors declare no conflict of interest.

\section{Abbreviations}

CSD: $\mathrm{Cu} / \mathrm{Zn}-\mathrm{SOD}$, copper/zinc superoxide dismutase; ORF: open reading frame; SOD: superoxide dismutase; DMSO: dimethylsulfoxide; SDS: sodium dodecyl sulfonate; ROS: reactive oxidate species; RT-qPCR: real-time quantitative polymerase chain reaction; IPTG: Isopropyl Isopropyl D-beta-thiogalactoside; PBS: phosphate-buffered saline; TBST: tris-buffered saline plus $0.1 \%$ tween 20; ECL: enhanced chemiluminescence; BSA: bovine serum albumin; GAPDH: glyceraldehyde 3-phosphate dehydrogenase; SD: standard deviations.

\section{References}

1. Donato, D.C.; Kauffman, J.B.; Murdiyarso, D.; Kurnianto, S.; Stidham, M.; Kanninen, M. Mangroves among the most carbon-rich forests in the tropics. Nat. Geosci. 2011, 4, 293-297. [CrossRef]

2. Liang, S.; Zhou, R.; Dong, S.; Shi, S. Adaptation to salinity in mangroves: Implication on the evolution of salt-tolerance. Chin. Sci. Bull. 2008, 53, 1708-1715. [CrossRef]

3. Berlyn, G.P. Coastal trees: The botany of mangroves. Science 1986, 234, 373. [CrossRef] [PubMed]

4. Ball, M.; Pidsley, S. Growth responses to salinity in relation to distribution of two mangrove species, Sonneratia alba and s. Lanceolata, in northern australia. Funct. Ecol. 1995, 77-85. [CrossRef]

5. Suzuki, M.; Yasumoto, E.; Baba, S.; Ashihara, H. Effect of salt stress on the metabolism of ethanolamine and choline in leaves of the betaine-producing Mangrove species Avicennia marina. Phytochemistry 2003, 64, 941-948. [CrossRef]

6. Jithesh, M.N.; Prashanth, S.R.; Sivaprakash, K.R.; Parida, A. Monitoring expression profiles of antioxidant genes to salinity, iron, oxidative, light and hyperosmotic stresses in the highly salt tolerant grey mangrove, Avicennia marina (forsk.) vierh. by mRNA analysis. Plant Cell Rep. 2006, 25, 865-876. [CrossRef] [PubMed]

7. Parida, A.K.; Das, A.B.; Mohanty, P. Investigations on the antioxidative defence responses to nacl stress in a mangrove, Bruguiera parviflora: Differential regulations of isoforms of some antioxidative enzymes. Plant Growth Regul. 2004, 42, 213-226. [CrossRef]

8. Miller, R.A.; Britigan, B.E. Role of oxidants in microbial pathophysiology. Clin. Microbiol. Rev. 1997, 10, 1-18. [PubMed]

9. Prashanth, S.R.; Sadhasivam, V.; Parida, A. Over expression of cytosolic copper/zinc superoxide dismutase from a mangrove plant Avicennia marina in indica rice var pusa basmati-1 confers abiotic stress tolerance. Transgenic Res. 2008, 17, 281-291. [CrossRef] [PubMed] 
10. Brouwer, M.; Brouwer, T.H.; Grater, W.; Brown-Peterson, N. Replacement of a cytosolic copper/zinc superoxide dismutase by a novel cytosolic manganese superoxide dismutase in crustaceans that use copper (haemocyanin) for oxygen transport. Biochem. J. 2003, 374, 219-228. [CrossRef] [PubMed]

11. Kochhar, S.; Kochhar, V.K. Expression of Antioxidant enzymes and heat shock proteins in relation to combined stress of cadmium and heat in Vigna mungo seedlings. Plant Sci. 2005, 168, 921-929. [CrossRef]

12. Cheeseman, J.M.; Herendeen, L.B.; Cheeseman, A.T.; Clough, B.F. Photosynthesis and photoprotection in mangroves under field conditions. Plant Cell Environ. 1997, 20, 579-588. [CrossRef]

13. Parida, A.K.; Das, A.B.; Mohanty, P. Defense potentials to nacl in a mangrove, Bruguiera parviflora: Differential changes of isoforms of some antioxidative enzymes. J. Plant Physiol. 2004, 161, 531-542. [CrossRef] [PubMed]

14. Lin, C.T.; Yeh, K.W.; Kao, M.C.; Shaw, J.F. Cloning and characterization of a cDNA encoding the cytosolic copper/zinc-superoxide dismutase from sweet potato tuberous root. Plant Mol. Biol. 1993, 23, 911-913. [CrossRef] [PubMed]

15. Scioli, J.R.; Zilinskas, B.A. Cloning and characterization of a cDNA encoding the chloroplastic copper/zinc-superoxide dismutase from pea. Proc. Natl. Acad. Sci. USA 1988, 85, 7661-7665. [CrossRef] [PubMed]

16. Kaminaka, H.; Morita, S.; Yokoi, H.; Masumura, T.; Tanaka, K. Molecular cloning and characterization of a cDNA for plastidic copper/zinc-superoxide dismutase in rice (Oryza sativa L.). Plant Cell Physiol. 1997, 38, 65-69. [CrossRef] [PubMed]

17. Cui, H.; Zhang, T. Application of SOD in Food and Cosmetic and Its Production by rmentation. Pharm. Biotechnol. 2000, 7, 187-189. (In Chinese).

18. Dutta, S.; Padhye, S.; Ahmed, F.; Sarkar, F. Pyridazolate-bridged dicopper (II) sod mimics with enhanced antiproliferative activities against estrogen and androgen independent cancer cell lines. Inorg. Chim. Acta 2005, 358, 3617-3624. [CrossRef]

19. Madamanchi, N.R.; Vendrov, A.; Runge, M.S. Oxidative stress and vascular disease. Arterioscl. Throm. Vas. 2005, 25, 29-38. [CrossRef] [PubMed]

20. Edeas, M.A.; Emerit, I.; Khalfoun, Y.; Lazizi, Y.; Cernjavski, L.; Levy, A.; Lindenbaum, A. Clastogenic factors in plasma of HIV-1 infected patients activate HIV-1 replication in vitro: Inhibition by superoxide dismutase. Free Radic. Biol. Med. 1997, 23, 571-578. [CrossRef]

21. Bafana, A.; Dutt, S.; Kumar, A.; Kumar, S.; Ahuja, P.S. The basic and applied aspects of superoxide dismutase. J. Mol. Catal. B Enzym. 2011, 68, 129-138. [CrossRef]

22. Lee, F.J.S.; Hassan, H.M. Biosynthesis of superoxide dismutase and catalase in chemostat culture of Saccharomyces cerevisiae. Appl. Microbiol. Biotechnol. 1987, 26, 531-536. [CrossRef]

23. Xie, X.; Pan, X.; Gong, L.; Chen, H.; Lin, L. Effects of Some Organic Solvents on the Activity and Conformation of Superoxide Dismutase (SOD) from Porcine Blood. J. Quanzhou Norm. Univ. 2010, 28, 47-50. (In Chinese).

24. Wang, F.; Li, X.Y.; Mo, X.M.; Zhang, G.; Sun, H.X. A biologically active vMIP-II-IgG3-TfN fusion protein, secreted from methylotrophic yeast pichia pastoris. Protein Express. Purif. 2013, 87, 47-54. [CrossRef] [PubMed]

25. Thomas, K.; Aalbers, M.; Bannon, G.A.; Bartels, M.; Dearman, R.J.; Esdaile, D.J.; Fu, T.J.; Glatt, C.M.; Hadfield, N.; Hatzos, C.; et al. A multi-laboratory evaluation of a common in vitro pepsin digestion assay protocol used in assessing the safety of novel proteins. Regul. Toxicol. Pharm. 2004, 39, 87-98. [CrossRef] [PubMed]

26. Grattan, S.R.; Grieve, C.M. Salinity-mineral nutrient relations in horticultural crops. Sci. Hortic. 1998, 78, 127-157. [CrossRef]

27. Zhu, J.K. Regulation of ion homeostasis under salt stress. Curr. Opin. Plant Biol. 2003, 6, 441-445. [CrossRef]

28. Lee, D.H.; Kim, Y.S.; Lee, C.B. The inductive responses of the antioxidant enzymes by salt stress in the rice (Oryza sativa L.). J. Plant Physiol. 2001, 158, 737-745. [CrossRef]

29. Tsai, Y.C.; Hong, C.Y.; Liu, L.F.; Kao, C.H. Relative importance of na+ and cl- in nacl-induced antioxidant systems in roots of rice seedlings. Physiol. Plant. 2004, 122, 86-94. [CrossRef]

30. Mittler, R. Oxidative stress, antioxidants and stress tolerance. Trends Plant Sci. 2002, 7, 405-410. [CrossRef]

31. Van Breusegem, F.; Vranova, E.; Dat, J.F.; Inze, D. The role of active oxygen species in plant signal transduction. Plant Sci. 2001, 161, 405-414. [CrossRef] 
32. Sen Raychaudhuri, S.; Deng, X.W. The role of superoxide dismutase in combating oxidative stress in higher plants. Bot. Rev. 2000, 66, 89-98. [CrossRef]

33. Bandeoglu, E.; Eyidogan, F.; Yucel, M.; Oktem, H.A. Antioxidant responses of shoots and roots of lentil to nacl-salinity stress. Plant Growth Regul. 2004, 42, 69-77. [CrossRef]

34. Gomez, J.M.; Jimenez, A.; Olmos, E.; Sevilla, F. Location and effects of long-term nacl stress on superoxide dismutase and ascorbate peroxidase isoenzymes of pea (Pisum sativum cv. Puget) chloroplasts. J. Exp. Bot. 2004, 55, 119-130. [CrossRef] [PubMed]

35. Chen, S.F.; Zhou, R.C.; Huang, Y.L.; Zhang, M.; Yang, G.L.; Zhong, C.R.; Shi, S.H. Transcriptome sequencing of a highly salt tolerant mangrove species Sonneratia alba using illumina platform. Mar. Genom. 2011, 4, 129-136. [CrossRef] [PubMed]

36. Bao, Y.; Li, L.; Wu, Q.; Zhang, G. Cloning, characterization, and expression analysis of extracellular copper/zinc superoxide dismutase gene from bay scallop argopecten irradians. Fish Shellfish Immunol. 2009, 27, 17-25. [CrossRef] [PubMed]

37. Zhang, Q.F.; Li, Y.Y.; Pang, C.H.; Lu, C.M.; Wang, B.S. Nacl enhances thylakoid-bound sod activity in the leaves of c-3 halophyte Suaeda salsa L. Plant Sci. 2005, 168, 423-430.

38. Laemmli, U.K. Cleavage of structural proteins during the assembly of the head of bacteriophage T4. Nature 1970, 227, 680-685. [CrossRef] [PubMed]

39. Li, D.C.; Gao, J.; Li, Y.L.; Lu, J. A thermostable manganese-containing superoxide dismutase from the thermophilic fungus thermomyces lanuginosus. Extrem. Life Extreme Cond. 2005, 9, 1-6. [CrossRef] [PubMed]

40. Livak, K.J.; Schmittgen, T.D. Analysis of relative gene expression data using real-time quantitative PCR and the $2^{-\Delta \Delta C \mathrm{t}}$ method. Methods 2001, 25, 402-408. [CrossRef] [PubMed]

(C) 2015 by the authors; licensee MDPI, Basel, Switzerland. This article is an open access article distributed under the terms and conditions of the Creative Commons by Attribution (CC-BY) license (http:/ / creativecommons.org/licenses/by/4.0/). 